\title{
ECONOMIC EFFECTS OF SMOKING BANS ON RESTAURANTS AND PUBS
}

\author{
Barrie Craven and Michael L. Marlow
}

The United Kingdom has recently enacted smoking bans in public places such as restaurants and pubs. Public health advocates argue that bans are necessary because non-smokers need protection from second-hand smoke. Advocates also claim that bans do not exert harm on owners because of a vast empirical literature showing that restaurants and bars in the United States never suffer harm following bans. This paper examines whether these claims are true by developing a model within the Coasian framework whereby owners of businesses have incentives to deal with smoking disputes between smokers and non-smokers. Our model demonstrates that it is incorrect to argue that smoking bans are necessary because the private market has no method of attempting to solve smoking problems. It also predicts that bans exert different effects on different businesses: some will be unaffected while others will experience losses or gains. Our literature review reveals that predictions of differential effects are consistent with the empirical evidence.

\section{Introduction}

Public health advocates argue that bans are necessary because non-smokers need protection from second-hand smoke. The United Kingdom recently enacted smoking bans in public places such as restaurants and pubs (Scotland, 26 March 2006; Wales, 2 April 2007; Northern Ireland, 30 April 2007; and England, 1 July 2007), where a major concern was for the health of employees in such establishments. Advocates also claim that such bans do not harm business owners because of a vast empirical literature showing that restaurants and bars in the United States never suffer harm following bans (Glantz, 2007). In fact, advocates often claim that bans improve sales at restaurants and bars and so, in effect, owners should thank them for promoting bans.

This paper focuses on whether smoking bans harm owners of restaurants, pubs, social and tombola clubs in the hospitality industry. We do not dwell on the issue of protecting employees from possible ill-health effects from passive smoking for two reasons. First, smoking itself is legal and if government was serious about 'health and safety' it would act on the primary source of the problem. Second, in competitive labour markets, characteristic of those in the hospitality industry, workers who do not wish to be exposed to passive smoking could choose to work in other establishments. The issue would be different, just as it would be for issues of racial and sexual equality, if the employers were monopsonistic purchasers of labour but this is emphatically not the case here.

We develop our model within the Coasian framework whereby owners of businesses have incentives to deal with smoking disputes between smokers and non-smokers. This model has two important predictions. One, owners attempt to deal with smoking disputes prior to the enactment of bans and therefore it is incorrect to argue that bans are necessary because the private market has no method of attempting to solve smoking problems. Two, smoking bans are expected to exert different effects on different businesses so that it is inappropriate to estimate aggregate effects of bans on businesses. Some businesses will be unaffected while others will experience losses or gains. We argue that studies showing no harm are not as unbiased or scientific as many researchers claim. We also raise the issue of whether claims of harm from second-hand smoke in restaurants and bars are based on sound evidence because this argument is often an important reason given by ban advocates for government intervention. 


\section{The Coase theorem and smoking bans}

Private markets are argued to fail when externalities are present because resource allocation takes place without full consideration of all costs and benefits. For example, a negative externality arises when Roger, who smokes, does not compensate Elaine, a non-smoker, when they sit near each other in a restaurant. The conventional viewpoint, or what is commonly referred to as the Pigouvian approach, simply singles out Roger as the source of the externality thus leading to the conventional solution that Roger needs to be taxed or regulated. A ban on smoking is one such regulation. Ronald Coase (1960), however, introduced the notion of the 'reciprocal nature of externalities' whereby both parties involved believe that the other is the source of the problem. Roger does not like Elaine complaining about his smoking and Elaine does not enjoy smoking by Roger. This key insight is critical to understanding that both Roger and Elaine have incentives to deal with each other over their dispute since Roger enjoys smoking and Elaine does not want to inhale any of Roger's smoke. A private market therefore attempts to resolve externality problems. Coase argued that, in the absence of transactions costs, negotiation achieves an efficient solution as long as resources are privately owned and transferable.

At first glance, it appears there are no means to settle putative conflicts between Roger and Elaine since the Coase theorem demonstrates that an efficient solution requires both low transactions costs between disputers and well-defined property rights to scarce resources. In fact, it is commonplace for ban advocates to argue that transactions costs are so prohibitive that we can simply quit all further efforts at applying the Coase theorem to smoking in restaurants or bars. An early dismissal is contained in a health economics textbook (Phelps, 1992, p. 430), that states:

\footnotetext{
'Trying to use agreements ... between people in a restaurant to determine whether smoking would take place would be the height of absurdity, and nobody would think seriously of a full "property rights" approach to such a problem. The transactions costs of reaching agreements would overwhelm the problem.
}

End of discussion, since bans must be the only solution.

So are transactions costs so prohibitive? Clearly, it is unreasonable to expect smokers and non-smokers to continually engage in negotiation with one another over use of air spaces. But, we must remember that neither of these two users of airspace are its owners. The owner of a restaurant or bar owns the airspace and, as such, has strong financial incentives to allocate this scarce resource efficiently. Owners, in effect, mediate between two demanders - smokers and nonsmokers - over how much smoking to allow within their establishments. Owners allocate air spaces to highest-valued users. In some cases, they may voluntarily forbid all smoking when many of their customers prefer no smoking. Other cases will arise where owners 'accommodate' diverse smoking preferences by offering separate rooms, smoking/non-smoking sections, and improving air filtration systems.

The Coase theorem is represented diagrammatically in Figure 1. $D r D r^{\prime}$ represents the diminishing marginal value for Roger of each additional cigarette he smokes. $\mathrm{CeC} e$ shows the

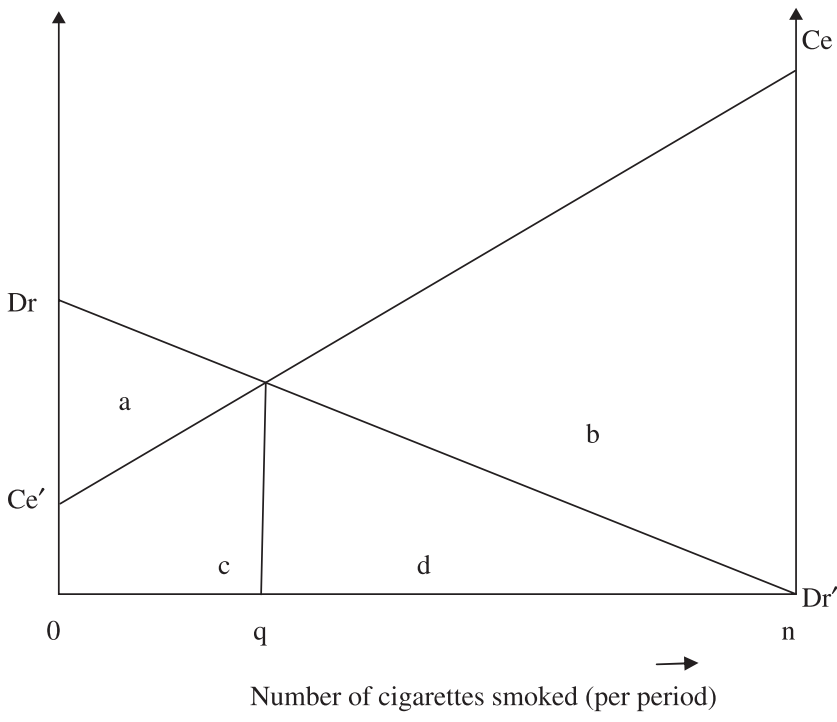

Figure 1: Property rights and bargaining limits

rising marginal discomfort to Elaine of each additional cigarette smoked by Roger. It is clear that the optimal number of cigarettes smoked is $\mathrm{o} q$. If the property right to the airspace lies with Roger, he would be willing to accept value $d$ and Elaine would be willing to pay up to value $d+b$ for Roger to reduce smoking from on to o $q$ cigarettes. If the property right lies with Elaine, she would be willing to accept $c$ and Roger would be willing to pay up to $c+a$ to be allowed to increase smoking from zero up to o $q$ cigarettes. Only if Elaine's discomfort schedule intersected the left vertical axis above $D r$ would the outcome be the same as a ban.

As long as owners desire maximum profit, own their airspace and mediate conflicts between smokers and non-smokers, it is reasonable to expect that private markets are paying attention to the smoking preferences of their customers and there is no reason to predict that all owners allocate resources in identical ways. In other words, claims by ban advocates that private owners can never deal with the smoking issue are clearly wrong.

One of us (Marlow) has published five peer-reviewed articles demonstrating the depth of private markets in accommodation. A brief summary of their findings has been provided below: ${ }^{1}$

- Owners offer more non-smoking seating, better ventilation and other accommodations when servicing fewer smoking customers.

- Some owners voluntarily ban all smoking, but others allow smoking throughout or dedicate areas where smoking is not allowed.

- The probability that a jurisdiction has a ban is positively related to the non-smoking share of the population, so bans are endogenous and tend to be enacted 'after the fact' in that private markets have already been re-allocating resources from smokers towards non-smokers.

The available research does not prove that private markets fully internalise all smoking problems. This issue, however, can best be studied with data on how private markets deal with smoking. The evidence does reveal a private market where owners allocate resources in directions consistent with 
economic theory and therefore predicts that, as smokers dwindle in numbers, smokers will continue to lose ground to non-smokers in their fight for airspaces within businesses.

An important implication of this private market in accommodation is that bans will exert different effects on different businesses. These same studies find evidence of the following effects:

- Owners with more smoking customers predict losses more often than those with few smoking customers.

- Owners adjust prices, wages, hours of operation and other business attributes in response to bans and so bans also affect customers and workers.

- Smoking bans are not fully enforced, and it is predictable that compliance is inversely related to the degree of harm imposed on owners.

- Bars, social and tombola clubs experience more harm than restaurants because they cater more to social interactions between smoking and non-smoking patrons.

- Bans are mostly adopted in jurisdictions with fewer smokers, so jurisdictions that ban smoking experience less harm than if bans were forced on jurisdictions with more smokers.

So, empirical evidence exists that smoking bans will affect different businesses differently and there is little logic to claims that all businesses will either suffer no harm or may even gain. The market process evolves over time and it is undoubtedly true that owners expend greater accommodation efforts now than in the past, simply because they pursue maximum profits in an environment where non-smokers are gaining ground on smokers over use of airspaces. Those who are impatient or intolerant of smokers, and whose ideological sensibilities lead them to discount the ability of private markets to resolve smoking disputes, are predisposed to concluding that bans are necessary.

Recent evidence of the effects of bans in Scotland reaches similar conclusions. Adda et al. (2007) estimated the short-run economic impacts of the Scottish smoking ban on public houses. They compared the sales and number of customers in public houses located in Scotland before and after the Scottish smoking ban was introduced, relative to a control group of establishments across the English border where no ban was imposed. They collected data on 2,724 pubs (1,590 in Scotland and 1,134 in Northern England) by phone interviews using quota sampling. They found that the Scottish ban led to a $10 \%$ decrease in sales and a $14 \%$ decrease in customers.

A recent news story discusses how one German bar owner dealt with a ban on smoking by cutting holes in his walls so that customers could literally stick their heads out to smoke cigarettes. ${ }^{2}$ Each smoker was provided three holes, one each for their head and their two hands. Smoking customers were then free to stick their heads and hands out to enjoy their cigarettes. The owner also mounted a curtain to protect smoking customers from the cold. Following the implementation of the ban in England there was a very marked increase in the sales and constructions of gazebos thus providing attractive sheltered smoking areas with patio heaters in beer gardens. The following letter appeared in the Daily Telegraph, 31 July 2007:

'Sir - Overheard at the bar of my local [pub] as I ordered a pint: "Well, I can stay here and be bored or go outside for some passive smoking and a chat." We left together to join the crowd in the smoking shed, leaving the bar empty.'

We add these stories to make two points. First, the fact that an owner finds it necessary to accommodate smoking customers in this manner strongly suggests that full enforcement of the ban would lower profits. Second, costs associated with this circumvention of the ban should not be ignored when we examine benefits and costs of bans.

\section{Equity and cigarette bans}

It is well known that smoking is disproportionately associated with lower socio-income groups. Smoking bans therefore adversely affect the working classes more than the better-off. We have also seen that non-smokers, mainly the middle classes, are the ones leading the drive towards smoke-free laws in the UK. It is also interesting to note, in the Coasian context, how pub chain giant, Wetherspoons, voluntarily introduced a no-music ban and then a smoking ban which was in place two years before legislation became law. Whilst popular attention has focused on restaurants and pubs, the ban will have a big impact on the two types of institutions which are especially associated with the working classes: the Working Men's Club and Institute Union (CIU, founded in 1862) and Bingo (tombola) Clubs. Most CIU clubs are historically associated with the working man who likes to drink and smoke (in many cases without any women in the bar). The CIU clubs are more than just drinking holes; they provide social meeting places for the community. It has been estimated that one in five working men's clubs in England and Wales fear they will be forced to close as a result of the smoking ban and that $83 \%$ would see takings fall. On the other hand, bingo clubs are mainly patronised by working-class smoking women. Mecca, one of the largest operators of bingo halls, estimates half of its patrons are smokers. Like the CIU clubs, bingo halls are social meeting places for low-income women where they can gossip and interact with friends whilst having the chance of leaving with windfall winnings. It is easily forgotten that the smoking culture is a socialising activity. It is perhaps not a coincidence that when smoking was at its peak in the middle of the last century, when about $75 \%$ of the adult population smoked, that social cohesion was also at its strongest.

\section{How do ban advocates show that bans exert no harm? ${ }^{3}$}

A fairly large empirical literature reports that bans exert no adverse effects on owners. Some studies even advance arguments that bans raise profits so much that owners should, in effect, thank ban advocates for raising their wealth. A recent literature review states

\footnotetext{
'... the vast majority of studies find that there is no negative economic impact of clean indoor air policies, with many findings that there may be some positive effects on local businesses.'
}

(Eriksen and Chaloupka, 2007, p. 375)

We now examine how these economic studies arrive at these conclusions. 
As discussed, economic theory predicts that bans exert differential effects on businesses, thus leading to the research question: how many firms gain, lose or are unaffected? This is not the question examined by researchers claiming that bans exert no harm. Most studies employ a 'community effects' methodology that aggregates all businesses into one number and then examines whether this aggregate changes following a ban. The examination becomes: do aggregate sales or tax revenues rise, fall or stay the same following a ban? Studies routinely conclude that sales and tax revenues never fall, but rise or stay the same.

The 'community effects' methodology bypasses the interesting question of: how many owners gain, lose or suffer no ill effects from bans? This method is like looking at a classroom of 30 students, and after observing that average weight is 160 pounds, concluding that no changes occurred over the following ten years because average weight remained 160 pounds. Meanwhile, some students gained 20 pounds, some lost 10 pounds, and still others exhibited no change. This is not a meaningful analysis, but nonetheless is employed in most studies that conclude that bans harm no business. There could be a defence of the 'community effects' approach, but we have never seen one because these studies never explain what this methodology ignores.

\section{Is 'scientific' research on adverse health consequences of second-hand smoke pure?}

We suspect some readers believe we have taken a rather cavalier attitude towards the adverse health effects of secondhand smoke. It must be true that non-smokers are at serious risk from second-hand smoke because we have heard this warning countless times. However, while we do not argue that there is zero health risk, the literature remains somewhat unsettled about how great risks are. An extremely thorough sceptical review of the risks from environmental tobacco smoke can be found in Nilsson's contribution to What Risk? Science, Politics and Public Health (Bate, 1997). It is undoubtedly true that environmental tobacco smoke contains carcinogens, as does coffee, as any search engine will demonstrate, and virtually everything we eat, but the issue is the magnitude of the risk.

Siegel (2007), an epidemiologist and long-time ban advocate, discusses what he refers to as the wild claims of many ban advocates regarding the adverse health effects of secondhand smoke and discusses how he has been personally attacked for criticising such claims. Siegel argues that anti-tobacco activists have been very busy over-estimating adverse health effects so that they will find little resistance from the public over their push for smoking bans.

\footnotetext{
'The general approach has been to attack ad hominem, rather than to directly confront the arguments being made. For this reason, I have come to the impression that the tobacco control movement does not allow room for any difference of opinion, and that those who dissent with any aspect of the prevailing wisdom must be discredited, attacked and silenced. I sense a rather McCarthyistic element in the tobacco control movement. Whether the scientific arguments I have made are valid or not is up for question and debate; the unwillingness of the movement to be willing to entertain a discussion of the validity of its
}

scientific claims, on the other hand, is a dangerous element in a public health movement.'

(Siegel, 2007, p. 20)

Siegel fears:

'The dissemination of inaccurate information by anti-smoking groups to
the public in support of smoking bans is unfortunate because it may
harm the tobacco control movement by undermining its credibility,
reputation, and effectiveness.'

(Ibid., p. 24)

Carl Phillips, an epidemiologist at the University of Alberta, has also written about personal and financial attacks levelled against him because he has also been vocal about what he perceives as junk science in the study of ETS (environmental tobacco smoke):

'There is little doubt that inhaling smoke is unhealthy, but equally clear evidence shows that we can only demonstrate disease risk from ETS for those at the highest level of exposure. The evidence about health effects of smoke and the legitimate aesthetic objection to involuntary ETS exposure are quite sufficient to justify prohibiting indoor smoking in public places, though clearly insufficient to justify public policies that prohibit voluntary low-level ETS gain. The activists involved, many of whom hold titles that indicate that they should behave as scientists and academics, appear unconcerned about subverting science to further their worldly agendas, hurting the careers of honest scientists, driving students away from politically controversial fields, attacking the principles of free academic research, and threatening the reputation of epidemiology as a field.'

(Phillips, 2007)

\section{Risk perception and real risk}

It is well known that the public perception of risk is often at variance with the evidence (Slovic et al., 1980). There are three types of risk: those that are directly perceptible such as accidents from traffic; those that require use of science for evaluation such as risks from cholera or influenza; and those, virtual risks, where there is doubt or a lack of knowledge among scientists such as the risks from BSE/CJD and environmental hazards (Adams, 1997). The risks from ETS seem to lie in the virtual category. Responses to virtual risk are likely to be influenced by pressure groups such as health campaigners who are likely to argue for prohibitions regardless of cost. Liberals, on the other hand, will tend to argue that such regulations are an infringement of liberty and should be minimised. Policy responses to virtual risks require politicians to seek expert advice. Experts, however, because they are specialists tend to give a high priority to their own expertise to the exclusion of competing specialists with competing interests and the broader interest (Craven et al., 1994). Where, as in the case of ETS, the medical evidence has generated wide variations in estimates of the extent to which individuals are harmed the conditions are propitious for interest groups to take the moral high ground and advocate draconian action. But even when regulations are imposed individuals will take avertive action (perhaps by smoking more at home rather than in a social setting or even by disobeying the law). When wearing seat belts was made compulsory in cars, drivers drove faster so that the rate of accidents tended to remain constant. 
A good example of how easy it is to distort the divergence of perception of risk from actual risk is found in the following story. In 1997, Nathan Zohner, a 14-year-old schoolboy from Idaho, surveyed his classmates about a chemical called dihydrogen monoxide. This compound contributes to: the 'greenhouse effect', the erosion of our natural landscape, corrosion and rusting of many metals and is found in excised tumours of terminal cancer patients. Despite this it is used: as a fire retardant, in pesticides, and as an additive of many junk foods and other food products. Forty-three of 50 students surveyed said the substance should be banned. The substance is water. The term 'Zohnerism' is used to refer to a true fact being used by a scientifically ignorant public to generate a false conclusion.

\section{Conclusions}

This article has applied the Coase theorem to the case of smoking bans and predicts that there is an active private market in dealing with smoking issues and that smoking bans will exert different economic effects on different types of businesses. This application is apparently not popular among the many researchers who claim that bans never harm any business. We have also shown that the many studies showing no harm do not really show this result since their methodology ignores effects on individual businesses because they distill all effects - positive, negative and neutral - into one number that is incapable of demonstrating no harm.

We find it curious that, while most economists would never claim that zero air or water pollution is a meaningful goal, they argue just this in the case of smoking in restaurants and pubs. Arguments for zero smoking must mean no costs are ever incurred when owners are forced to clean all smoke in their airspace. Losing customers or sales following a ban, or lost welfare of smokers, can clearly be considered a cost of clean-up. A more informed policy might allow a finite number of smoking 'licences' to be auctioned off in jurisdictions whereby owners whose businesses benefit the most from smoking can retain property rights over their airspace. Ban advocates never argue for this policy, but of course entertaining this argument also acknowledges that bans might harm some businesses. An auction approach also presumes an understanding of Coase's logic concerning importance of private resource ownership as well as the 'reciprocal nature of externalities'.

We also find it curious that ban advocates have taken the tactic of showing no harm, when this is clearly nonsense. A more appropriate question might be: what level of harm would be acceptable for us to ban all smoking in restaurants and pubs? Harm exerted on $5 \%, 10 \%$ or $20 \%$ of businesses, for example? Indeed, low levels of harm would likely still attract broad support for bans. But ban advocates keep insisting that harm is zero. It is as if advocates somehow worry that a candid discussion of costs and benefits would somehow derail future ban adoptions. This is doubtful given long-standing declines in smoking that are likely to persist. Of course, an understanding of private markets would predict something similar, but at a pace apparently too slow for ban advocates. Moreover, the predicted level of harm from bans is likely to diminish over time as well, simply because there will probably be fewer smokers.
1. See Boyes and Marlow (1996) and Dunham and Marlow (2000a, 2000b, 2003, 2004)

2. See http://www.ananova.com/news/story/sm_2655704.html (27 December 2007).

3. Marlow (2008) provides a detailed discussion of the many problems associated with this literature.

\section{References and bibliography}

Adams, J. (1997) 'Cars, Cholera, Cows and Contaminated Land: Virtual Risk and the Management of Uncertainty', in R. Bate (ed.) What Risk? Science, Politics and Public Health, Oxford: ButterworthHeinemann.

Adda, J. and F. Cornaglia (2006a) 'The Effect of Taxes and Bans on Passive Smoking', Discussion Paper No. 509, Centre for Economic Policy Research, Australian National University, January.

Adda, J. and F. Cornaglia (2006b) 'Taxes, Cigarette Consumption, and Smoking Intensity', American Economic Review, 96, 1013-1028.

Adda, J., S. Berlinski and S. Machin (2007) 'Short-run Economic Effects of the Scottish Smoking Ban', International Journal of Epidemiology, 36, 149-154.

Bate, R. (1997) What Risk? Science, Politics and Public Health, Oxford: Butterworth-Heinemann.

Boyes, W. J. and M. L. Marlow (1996) 'The Public Demand for Smoking Bans', Public Choice, 88, 57-67.

Buddelmeyer, H. and R. Wilkins (2005) 'The Effects of Smoking Ban Regulations on Individual Smoking Rates', Discussion Paper No. 1737, University of Melbourne, September.

Coase, R. H. (1960) 'The Problem of Social Cost', Journal of Law and Economics, 3 (October), 1-44.

Craven, B. M., G. T. Stewart and M. Taghavi (1994) 'Amateurs Confronting Specialists: Expenditure on AIDS in England', Journal of Public Policy, 13, 305-325.

Dunham, J. and M. L. Marlow (2000a) 'Smoking Laws and the Allocation of Restaurant and Bar Seating', Economic Inquiry, 38, 151-157.

Dunham, J. and M. L. Marlow (2000b) 'The Differential Effects of Smoking Laws on Restaurants, Bars and Taverns', Contemporary Economic Policy, 18, 326-333.

Dunham, J. and M. L. Marlow (2003) 'The Economic Incidence of Smoking Restrictions', Applied Economics, 35, 1935-1942.

Dunham, J. and M. L. Marlow (2004) 'The Private Market for Accommodation', Eastern Economic Journal, 30, 377-391.

Eriksen, M. and F. Chaloupka (2007) 'The Economic Impact of Clean Indoor Air Laws', CA: A Cancer Journal for Clinicians, 57, 367-378.

Glantz, S. A. (2007) 'Commentary: Assessing the Effects of the Scottish Smokefree Law - The Placebo Effect and the Importance of Obtaining Unbiased Data', International Journal of Epidemiology, 36, 155-156.

Marlow, M. L. (2008) 'Honestly, Who Else Would Fund Such Research?', Econ Journal Watch, 5, 240-268.

Orzechowski, W. and R. C. Walker (2006) The Tax Burden on Tobacco: Historical Compilation 2005, Arlington, VA: Orzechowski and Walker.

Phelps, C. E. (1992) Health Economics, New York: HarperCollins.

Phillips, C. V. (2007) 'Warning: Anti-tobacco Activism May Be Hazardous to Epidemiologic Science', Epidemiologic Perspectives and Innovations, 4, 13.

Scollo, M., A. Lal, A. Hyland and S. Glantz (2003) 'Review of the Quality of Studies on the Economic Effects of Smoke-free Policies on the Hospitality Industry', Tobacco Control, 12, 13-20.

Siegel, M. (2007) 'Is the Tobacco Control Movement Misrepresenting the Acute Cardiovascular Health Effects of Secondhand Smoke Exposure?', Epidemiologic Perspectives and Innovations, 4, 12.

Slovic, P., B. Fischoff and S. Lichenstein (1980) 'Facts and Fears: Understanding Perceived Risk', in R. C. Schwing and W. A. Albers Jr. (eds.) Societal Risk Assessment: How Safe is Safe Enough?, New York: Plenum Press.

Thun, M. J., C. A. Lally, J. T. Flannery, E. E. Calle, W. D. Flanders and C. W. Heath, Jr. (1997) 'Cigarette Smoking and Changes in the Histopathology of Lung Cancer', Journal of the National Cancer Institute, 89, 1580-1586. 